Revista Brasil. Bot., V.27, n.4, p.615-619, out.-dez. 2004

\title{
Duas novas espécies de Calliandra Benth. (Leguminosae - Mimosoideae) da Chapada Diamantina, Bahia, Brasil ${ }^{1}$
}

\author{
ÉLVIA R. SOUZA ${ }^{2,3}$ e LUCIANO P. QUEIROZ ${ }^{2}$
}

(recebido: 21 de agosto de 2003; aceito: 17 de junho de 2004)

\begin{abstract}
Two new species of Calliandra Benth. (Leguminosae - Mimosoideae) from the Chapada Diamantina, Bahia, Brazil). Two new species of Calliandra are described from the Chapada Diamantina, state of Bahia, eastern Brazil. Calliandra geraisensis E.R. Souza \& L.P. Queiroz is related to C. calycina Benth. but it differs in its depauperate habit, distichous leaves and absence of glandular trichomes on the perianth. Calliandra imbricata E.R. Souza \& L.P. Queiroz is a shrubby plant similar to $C$. erubescens Renvoize from which it differs by having the leaves with more pinnae and more leaflets and by its red stamens. Both species occur in the mountains of the Chapada Diamantina region and are narrow endemics from a small area near the town of Piatã.
\end{abstract}

Key words - Calliandra, Ingeae, taxonomy

RESUMO - (Duas novas espécies de Calliandra Benth. (Leguminosae - Mimosoideae) da Chapada Diamantina, Bahia, Brasil). São descritas duas novas espécies de Calliandra da Chapada Diamantina, Estado da Bahia, leste do Brasil. Calliandra geraisensis E.R. Souza \& L.P. Queiroz é próxima de C. calycina Benth., diferindo pelo seu hábito depauperado, folhas dísticas e ausência de tricomas glandulares no perianto. Calliandra imbricata E.R. Souza \& L.P. Queiroz é uma planta arbustiva semelhante a $C$. erubescens Renvoize, da qual difere pelas folhas com maior número de pinas e folíolos e pelos estames vermelhos. Ambas as espécies ocorrem nas montanhas da Chapada Diamantina e são endêmicas restritas de uma pequena área nas vizinhanças da cidade de Piatã.

Palavras-chave - Calliandra, Ingeae, taxonomia

\section{Introdução}

O gênero Calliandra foi estabelecido por Bentham (1844) e inclui espécies da subfamília Mimosoideae com androceu polistêmone e monadelfo que possuem um tipo de legume caracterizado pela deiscência longitudinal elástica a partir do ápice e valvas com margens espessadas. $\mathrm{O}$ gênero foi recentemente revisado por Barneby (1998) que o expurgou dos elementos africanos e asiáticos de modo que, na sua atual circunscrição, é um grupo exclusivamente neotropical com 132 espécies.

A Chapada Diamantina é um dos principais centros de diversidade de Calliandra, onde ocorrem 40 espécies, sendo 30 delas endêmicas desta região (Souza 1999, Souza 2001). Destas espécies, 19 foram descritas a partir de 1980 (Renvoize 1981, Mackinder \& Lewis 1990, Barneby 1998) demonstrando o grau de desconhecimento florístico da região e a complexidade taxonômica do gênero. Nesta área ocorre um grande

\footnotetext{
1. Parte da dissertação de mestrado da primeira autora no Programa de Pós-graduação em Botânica da UEFS.

2. Universidade Estadual de Feira de Santana, Departamento de Ciências Biológicas, km 03 - BR 116, Campus, 44031-460 Feira de Santana, BA, Brasil.

3. Autor para correspondência: elviasouza@yahoo.com.br
}

maciço montanhoso que ocupa a maior parte da região central do Estado da Bahia, estendendo-se de cerca de $10^{\circ}-14^{\circ} \mathrm{S}$ e de $40^{\circ}-43^{\circ} \mathrm{W}$.

No curso de um levantamento das espécies de Calliandra da Chapada Diamantina (Souza 2001), foram encontradas duas espécies novas que são descritas e ilustradas a seguir.

Calliandra geraisensis E.R. Souza \& L.P. Queiroz, sp. nov. Tipo: BRASIL: BAHIA: Piatã, platô do alto da Serra da Tromba, ramal ao sul da estrada Piatã-Inúbia, Caminho da Ressaca, $13^{\circ} 03^{\prime}$ 'S e 41 ${ }^{\circ} 49^{\prime} \mathrm{W}, 1.300 \mathrm{msm}$, 2-XI-1996 (fl.), L.P. de Queiroz, D.J.H. Hind, H.P. Bautista \& M.M. da Silva 4706 (holótipo HUEFS). Figura 1.

Foliis ascendentibus et foliolis linearibus C. calycinae similis, sed habitu depauperato, ramis virgatis, foliis distichis laxisque et perianthio glabrato sine pubibus glandularibus solum calycis laciniis pubescentibus differt.

Subarbusto virgado ca. 0,6 m alt. com xilopódio robusto, amarelado; ramos, eixos foliares e pedúnculo densamente pilosos quando jovens, ramos envelhecidos glabros. Estípulas lanceoladas, 3-7 × 1-2 mm. Folhas sésseis, ascendentes, dísticas; pecíolo1-2 mm compr.; raque 5-7 mm compr.; pinas 2 pares, mais ou menos 


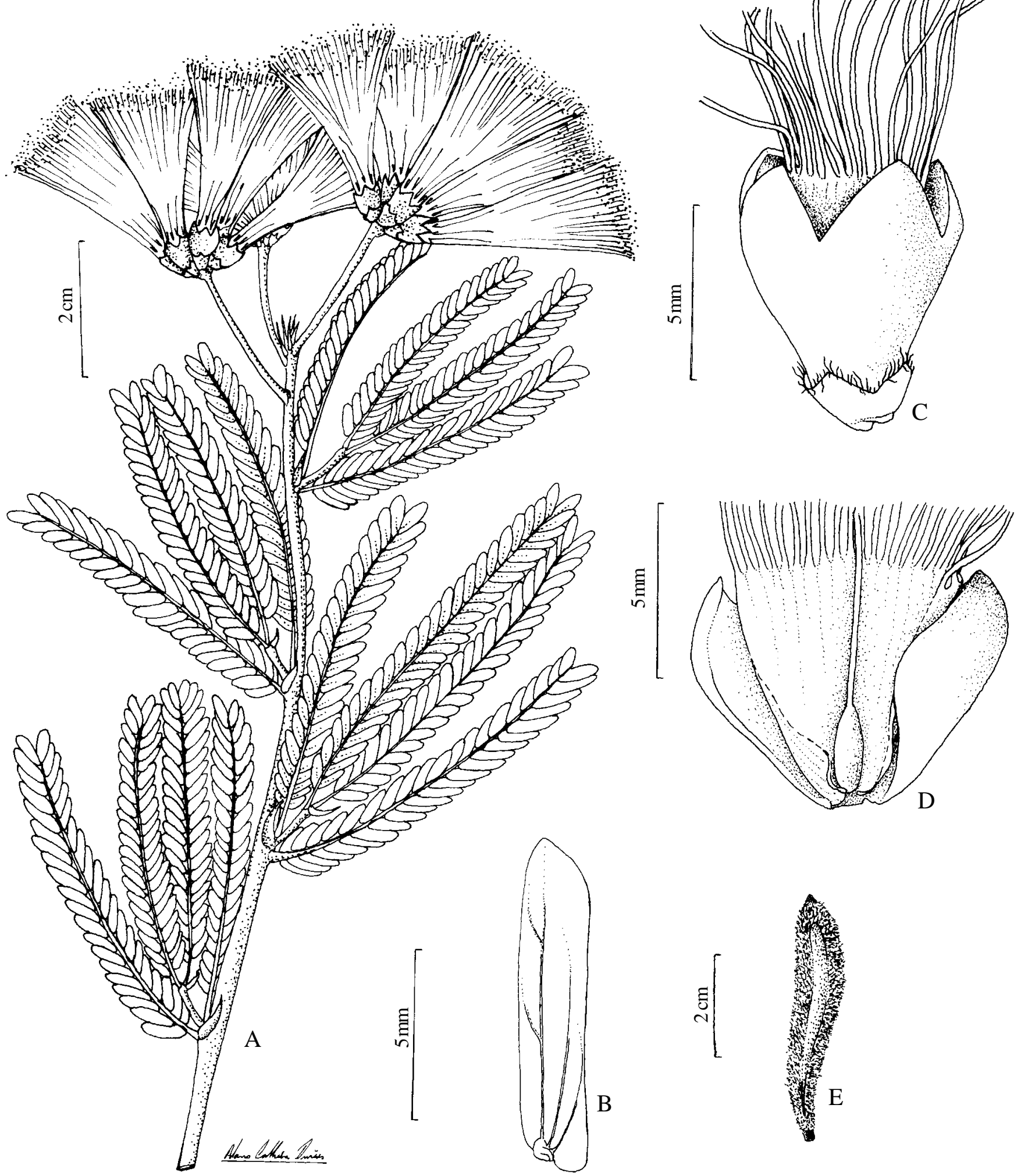

Figura 1. Calliandra geraisensis. A. hábito. B. folíolo, face abaxial mostrando os tricomas tectores e glandulares no detalhe. C. perianto. D. corte longitudinal do perianto e da base do tubo estaminal permitindo a visualização do ovário. E. fruto (Queiroz 4706).

Figure 1. Calliandra geraisensis. A. habit. B. leaflet, lower surface. C. perianth. D. opened perianth showing the base of the staminal tube and the ovary. E. fruit. (Queiroz 4706). 
equilongas, 4,5-5 cm compr.; folíolos 19-21 pares por pina, imbricados, 8-10 × ca. $2 \mathrm{~mm}$, coriáceos, oblongos a lineares, glabros, ápice obtuso, base truncada, oblíqua, assimétrica, nervação palmado-dimidiada, nervura principal excêntrica. Pseudoracemos terminais com fascículos de 1-2 glomérulos pedunculados; pedúnculo 18-22 mm compr. Flores 5 por glomérulo, homomórficas, tetrâmeras a pentâmeras, sésseis; cálice campanulado, tubo ca. 1,5 mm compr., glabro, lobos deltóides, ciliados, 0,5-0,6 mm compr.; corola glabra, campanulada, esverdeada, tubo 3-5 mm compr., lobos obtusos, vináceos, ca. $2 \mathrm{~mm}$ compr.; estames brancos, tubo estaminal 7-8 $\mathrm{mm}$ compr., parede interna do tubo estaminal nectarífera, estemonozona ca. $2 \mathrm{~mm}$ compr., filetes livres por 18-22 mm compr., anteras castanhas; nectário intraestaminal ausente; ovário obovado, glabro, ca. $2 \mathrm{~mm}$ compr., ca. 5-ovulado, estilete $23-28 \mathrm{~mm}$ compr., estigma capitado. Legume ca. 4,5 $\times 0,7 \mathrm{~cm}$, linear-oblanceolado, ápice arredondado, mucronado, base cuneada; valvas lenhosas, velutinas. Sementes não vistas.

Parátipo: BRASIL: BAHIA: Piatã, platô do alto da Serra da Tromba, ramal ao sul da estrada Piatã-Inúbia, Caminho da Ressaca, $13^{\circ} 03^{\prime} \mathrm{S}$ e $41^{\circ} 49^{\prime} \mathrm{W}, 1.300 \mathrm{msm}$, 2-XI-1996 (fl., fr.), L.P. Queiroz et al. 4705 (HUEFS). Ecologia e distribuição - Calliandra geraisensis é uma espécie endêmica da serra da Tromba, no município de Piatã. Ocorre em ambiente de campo cerrado praticamente sem árvores, sobre solo arenoso compactado a uma altitude de cerca de $1.300 \mathrm{msm}$. Este tipo de paisagem é localmente conhecido como "gerais", de onde é derivado o epíteto específico. Foi encontrado material florido e frutificado no mês de novembro.

Taxonomia - Calliandra geraisensis pertence à seção Calliandra (sensu Barneby 1998) e é mais semelhante a $C$. calycina Benth., uma espécie relativamente bem distribuída na Chapada Diamantina mas que, até o momento, não foi coletada na serra da Tromba (Souza 1999). Estas espécies aproximam-se pela disposição ascendente das folhas e folíolos lineares e contíguos. No entanto, $C$. geraisensis diferencia-se de C. calycina pelo hábito mais depauperado de subarbusto com xilopódio e ramos virgados, pelas folhas dísticas, laxamente dispostas nos ramos, e pelo perianto quase glabro, sem tricomas glandulares e com tricomas tectores apenas nos lobos do cálice, enquanto C. calycina, por sua vez, é um arbusto robusto com caule ramificado, folhas espiraladas fortemente congestas e imbricadas no ápice dos ramos e perianto esparsamente púberulo a glabro e com tricomas glandulares.
Calliandra imbricata E.R. Souza \& L.P. Queiroz, sp. nov. Tipo: BRASIL: BAHIA: Piatã, estrada Piatã-Inúbia a ca. 25 km NW de Piatã, $13^{\circ} 04$ ' $48^{\prime \prime}$ S e $41^{\circ} 55^{\prime} 59^{\prime \prime}$ W, 1.450 m, 23-II-1994 (f1.), P.T. Sano, S. Atkins, C.M. Sakuragui, R.M. Harley \& V.C. Souza CFCR 14433 (holótipo HUEFS; isótipos HUEFS, SPF).

Figura 2.

Habitu frutescenti, inflorescentia facie et foliolis oblongis vel obovatis palmatinervibus $\mathrm{C}$. erubescenti similis sed foliis pinnis (4-5) et pinnae foliolis (26-32) numerosioribus, foliolis parvioribus $(5-8 \times 3-4 \mathrm{~mm})$, perianthio pubibus glandularibus instructo et staminibus rubris statim diagnoscenda.

Arbusto ca. $1 \mathrm{~m}$ alt.; ramos, eixos foliares e pedúnculos pubérulos com indumento entremeado com tricomas glandulares avermelhados, ramos novos ferrugíneos. Estípulas foliáceas, lanceoladas, ca. $2 \times$ $1 \mathrm{~mm}$. Folhas pecioladas, não ascendentes, dísticas; pecíolo 0,8-1,2 cm compr.; raque 3,5-4,5 cm compr.; pinas 4-5 pares, mais ou menos eqüilongas, às vezes com as distais menores, pinas maiores $2,8-5,3 \mathrm{~cm}$ compr.; folíolos 7-16 pares, fortemente imbricados, dispostos de modo a que o folíolo anterior sobrepõe-se ao seguinte, os medianos mais ou menos equiilongos 5-8 $\times 3-4 \mathrm{~mm}$, os proximais e distais menores $3-5 \times$ 2-3 mm, coriáceos, obovados, face adaxial pubérula a glabrescente, face abaxial pubérula e com tricomas glandulares, ápice obtuso a arredondado, base truncada, assimétrica, nervação palmada, nervura principal excêntrica. Pseudoracemos terminais, exsertos da folhagem, constituídos por fascículos de 2-3 glomérulos pedunculados; pedúnculo 10-17 mm compr.; brácteas pedunculares ausentes; brácteas florais lanceoladas, ca. $2 \times 1 \mathrm{~mm}$. Flores 5 por glomérulo, homomórficas, pentâmeras, sésseis; cálice campanulado, com tricomas glandulares, tubo 1,8-2 mm compr., lobos deltóides, ca. 0,2 mm compr.; corola campanulada, com tricomas glandulares, tubo 2,8-5 mm compr., lobos obtusos, 2-2,2 mm compr.; estames vermelhos, tubo estaminal ca. $6 \mathrm{~mm}$ compr., estemonozona ca. 1,5 mm compr., filetes livres por 21-24 mm compr., anteras vináceas; nectário intraestaminal ausente; ovário obovado, pubérulo, 2-2,5 mm compr., ca. 5-ovulado, estilete ca. $30 \mathrm{~mm}$ compr., estigma capitado. Fruto não visto.

Ecologia e distribuição - Calliandra imbricata é uma espécie endêmica da Serra do Atalho, no município de Piatã. Da mesma forma que C. geraisensis, ocorre em ambientes de campos cerrados sobre solo arenoso entre rochas. Foi encontrado material florido no mês de 


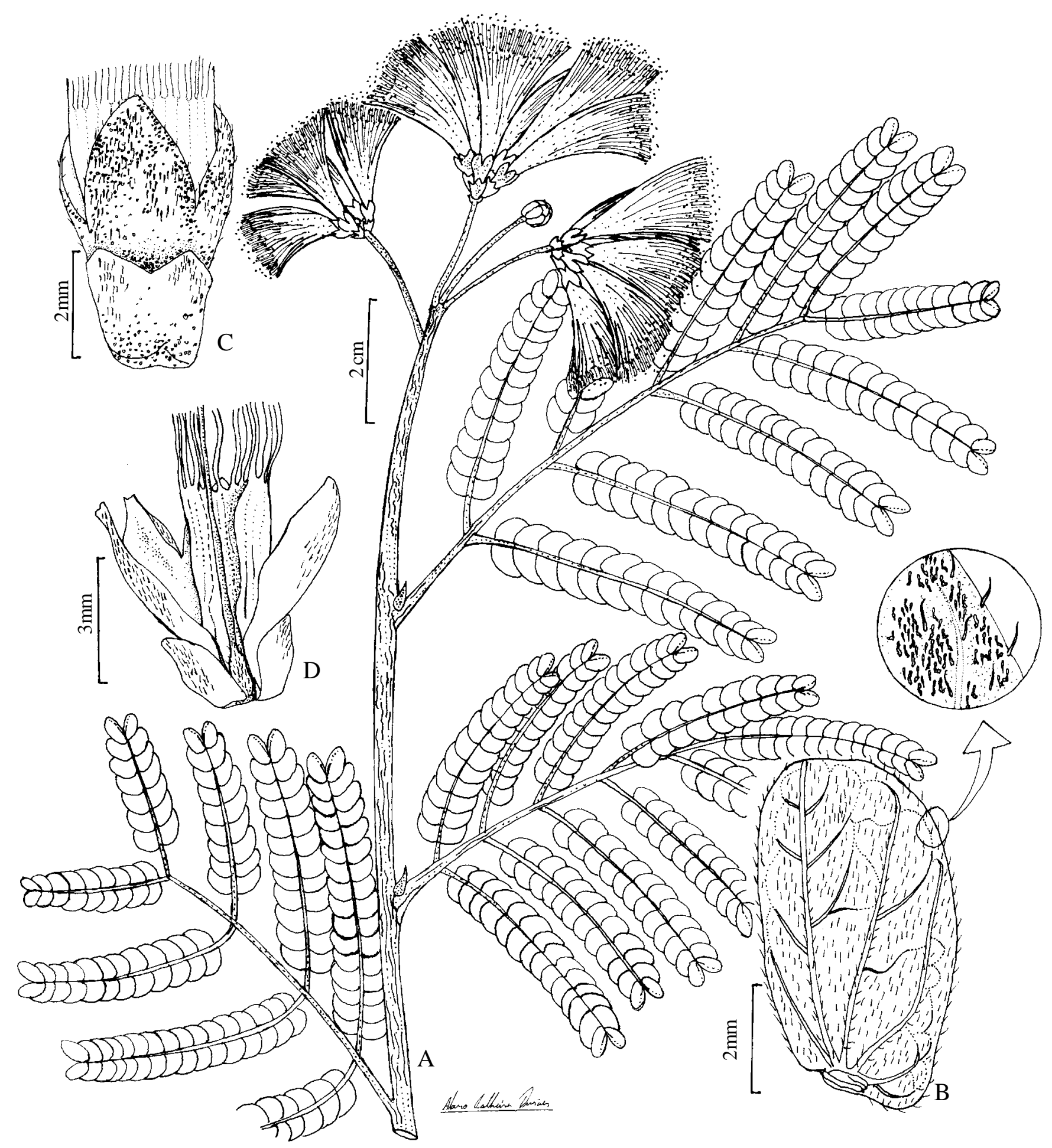

Figura 2. Calliandra imbricata: A. hábito. B. folíolo, face abaxial. C. flor ilustrando o perianto e a base do tubo estaminal. D. corte longitudinal do perianto e da base do tubo estaminal permitindo a visualização do ovário. (Sano CFCR 14433).

Figure 2. Calliandra imbricata: A. habit. B. Leaflet, lower surface showing glandular and non glandular trichomes in the detail. C. flower showing the perianth and the base of the staminal tube. D. opened perianth showing the base of the staminal tube and the ovary. (Sano CFCR 14433). 
fevereiro. A frutificação não foi observada.

Taxonomia - Calliandra imbricata pertence à seção Calliandra. Assemelha-se a $C$. erubescens Renv. no hábito arbustivo, arquitetura da inflorescência e folíolos oblongos a obovais com nervação palmada. No entanto, pode ser diferenciada pelas folhas com maior número de pinas, (4-5 pares v. 2-3 em C. erubescens), maior número de folíolos por pina, (26-32 v. 10-20 em C. erubescens), folíolos menores (5-8 $\times 3-4 \mathrm{~mm}$ v. 7-10 $\times 4-5 \mathrm{~mm}$ em $C$. erubescens), perianto com tricomas glandulares (v. ausentes em $C$. erubescens) e estames vermelhos (v. brancos em C. erubescens).

Agradecimentos - E.R. de Souza agradece à Capes pela concessão de bolsa de Mestrado e L.P. Queiroz ao CNPq pela bolsa de produtividade. As ilustrações foram preparadas por Alano Calheiras e as diagnoses latinas foram revisadas por Cássio van de Berg. O trabalho de campo foi apoiado pelo CNPq (Processo n. 520364/00-7).

\section{Referências bibliográficas}

BARNEBY, R.C. 1998. Silky tree, guanacaste, monkey's earring: a generic system for the synandrous Mimosaceae of the Americas. Memoirs of the New York Botanical Garden 74:1-223.

BENTHAM, G. 1844. Notes on Mimoseae. London Journal Botanical 3:82-112, 195-226.

MACKINDER, B.A. \& LEWIS, G.P. 1990. Two new species of Calliandra (Leguminosae - Mimosoideae) from Brazil. Kew Bulletin 45:681-684.

RENVOIZE, S.A. 1981. The genus Calliandra (Leguminosae) in Bahia, Brazil. Kew Bulletin 36:63-83.

SOUZA, E.R. 1999. O gênero Calliandra Benth. (Leguminosae - Mimosoideae) na região de Catolés, Bahia, Brasil. Monografia de especialização. Universidade Estadual de Feira de Santana, Feira de Santana.

SOUZA, E.R. 2001. Aspectos taxonômicos e biogeográficos do gênero Calliandra Benth. (Leguminosae Mimosoideae) na Chapada Diamantina, Bahia, Brasil. Dissertação de mestrado. Universidade Estadual de Feira de Santana, Feira de Santana. 